Article

\title{
A Case of Leveraging a Mega-Sport Event for a Sport Participation and Sport Tourism Legacy: A Prospective Longitudinal Case Study of Whistler Adaptive Sports
}

\author{
Tracey J. Dickson ${ }^{1, * \mathbb{D}}$, Simon Darcy $^{2}$ and Chelsey Walker ${ }^{3}$ \\ 1 Canberra Business School, University of Canberra, Canberra 2601, Australia \\ 2 UTS Business School, University of Technology Sydney, Ultimo 2007, Australia; Simon.Darcy@uts.edu.au \\ Whistler Adaptive Sports, Whistler, BC V8E 0K3, Canada; cwalker@whistleradaptive.com \\ * Correspondence: tracey.dickson@canberra.edu.au
}

Citation: Dickson, T.J.; Darcy, S.; Walker, C. A Case of Leveraging a Mega-Sport Event for a Sport Participation and Sport Tourism Legacy: A Prospective Longitudinal Case Study of Whistler Adaptive Sports. Sustainability 2021, 13, 170. https://doi.org/10.3390/su13010170

Received: 5 December 2020

Accepted: 19 December 2020

Published: 26 December 2020

Publisher's Note: MDPI stays neutral with regard to jurisdictional clai$\mathrm{ms}$ in published maps and institutional affiliations.

Copyright: $\odot 2020$ by the authors. Licensee MDPI, Basel, Switzerland. This article is an open access article distributed under the terms and conditions of the Creative Commons Attribution (CC BY) license (https:// creativecommons.org/licenses/by/ $4.0 /)$.

\begin{abstract}
Sport participation legacies are often offered as reasons to host mega-sport events, yet there is little evidence to demonstrate the claim's legitimacy, thus we examine "What did Whistler Sports do to leverage the Vancouver 2010 Olympic and Paralympic Winter Games to facilitate a sport tourism legacy?". Through a prospective longitudinal case study of WAS and application of the temporal extension of the socioecological framework, multiple data sources were analyzed from over a decade beginning before the event until 2019. The findings reveal the situated and embedded nature of mega-sport event legacies i.e., context. These depend upon a network of facilitators such as local, provincial, and federal policies; pre-event and post-event vision and strategies from local communities and sport organizations; the development of a pool of willing and flexible volunteers. Together these were strategically leveraged to overcome sport participation and sport tourism barriers for people with disabilities. The sport, tourism, and sport tourism experience reflected Whistler's natural and infrastructure advantage and the needs and desires of locals and visitors with access needs that could not have occurred without the capital injection of the Vancouver 2010 Olympic and Paralympic Games. Leveraging the mega-sport event opportunities required leadership and a strategic vision for repositioning to a year-round program. This strategic change also opened new sport and sport tourism opportunities for current participants but importantly brought new participants and their friendship groups to Whistler over the post-event decade for year-round sustainable adaptive sport opportunities.
\end{abstract}

Keywords: disability; sport participation; legacy; mega-sport event; Paralympic; sustainability

\section{Introduction}

Host communities are commonly told that after hosting mega-sport events (MSE), including the Olympic and Paralympic Games, beneficial social legacies would remain such as increased sport participation and physical activity (e.g., [1-4]). For parasport events the legacy potential is reflected in the International Paralympic Committee's (IPC's) Paralympic legacy goals including, "sport structures/organizations for people with an impairment, from grassroots to elite level" [5]. Despite these opportunities, community/grassroots, and para/disability sport participation and legacy research and practice languishes behind the mainstream $[6,7]$. This translates into more ad hoc approaches to disability sport and tourism, including event leveraging, through inadequate facilitating policies, poor policy operationalization, relatively underdeveloped sport development pathways, inadequate training resources, and inaccessible environments and transport [7-9].

For beneficial sport legacies to remain after MSEs across community and elite sport development pathways and whole-of-life participation, requires a strategic vision to leverage opportunities [10]. Converting the latent potential to an actual increase in sporting participation across the lifespan will also facilitate greater social impacts beyond sport [7,11,12]. 
To achieve these legacies the design, delivery, and leveraging of MSE must involve multilevel strategies across policies, programs, activities, interventions, facilities, built and natural environments to support the change [13]. These will target "individuals, social environments, physical environments, and policies" [14] (p. 63). Multilevel approaches parallel applications of socioecological frameworks (SEFs) applied elsewhere [15-18]. Legacies from parasport events may also facilitate sport tourism with participants enabled to travel and stay within MSE host communities, utilizing accessible environments, accommodation, and program offerings, thus enabling broader social and economic legacies [7]. However, most legacy research merely theorizes legacy or is conducted either too soon after the event to be deemed a legacy, or even before the event (e.g., [7,19-21]).

To redress the research gaps, we conducted a longitudinal prospective case study of Whistler Adaptive Sports (WAS) analyzed via a novel temporal extension of the SEF (TESEF) [13] to examine an example of how WAS leveraged a MSE for a parasport participation and tourism legacy. The case was examined before, during, and for nearly a decade after the Vancouver 2010 Olympic and Paralympic Winter Games (Vancouver2010). This research occurred over a period when Whistler's modest tourism growth was outpaced by WAS's phenomenal participation day growth (Figure 1). The enabling factors that facilitated and sustained WAS's legacy from Vancouver2010 are investigated and deconstructed below.

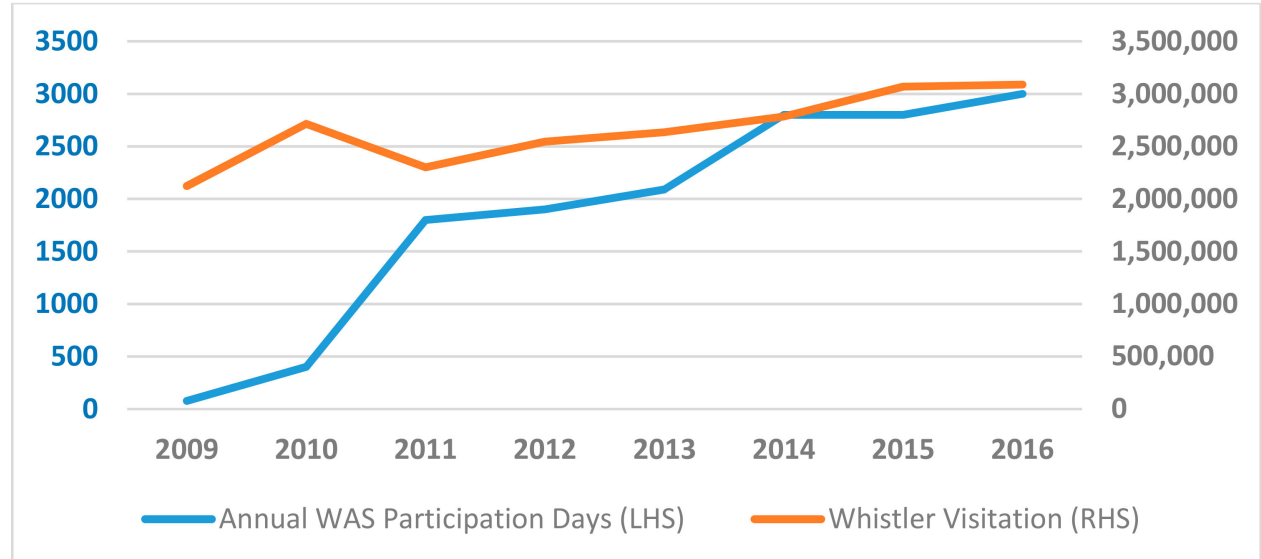

Figure 1. Whistler Adaptive Sport (WAS) annual lessons/participation days and Whistler visitation (data sources: WAS AGM Reports https:/ / whistleradaptive.com and RMOW https:/ / www.whistler. $\mathrm{ca} /$ municipal-gov / community-monitoring/whistler-facts-and-figures/whistler-visitation).

Following, we review the theoretical framework in which this research is situated, the conceptual framework used for analysis, i.e., the TESEF, then the research question and methods. The discussion draws together the case's threads and points the way forward for future research and practice for MSE legacies, identifying the research's methodological and practical implications.

With the various nomenclatures for people with disability $(\mathrm{PwD})[22,23]$ and their sporting contexts, such as disability sports, parasports, adaptive sports, and inclusive sports, the preference is to use the language of the case study, thus 'adaptive sports' is used from hereon.

\subsection{Theoretical Framework}

As this case is focused upon adaptive sport participation and tourism as a Vancouver2010 legacy, the theoretical framework considers legacies and leveraging, adaptive sports, and constraints to participation by $\mathrm{PwD}$. 


\subsubsection{Legacies and Leverage}

Legacies are what remains after the MSE and are event-centered, while leveraging relates to the strategic planning and activities to achieve beneficial MSE outcomes $[24,25]$. The panoply of MSE legacies include infrastructure (stadia, roads, and transport); volunteering and sport participation growth; and enhanced destination competitiveness [7,19,26,27]. As explored in Figure 2 the level of planning, scale, cost, and temporal and spatial dimensions of legacies may vary, as does whether it is considered positive or negative [27]. Crucially, for legacy research and practice, the legacy radar or web [27] expands previous legacy frameworks by adding the spatial and temporal dimensions $[27,28]$. The sport participation outcome explored here would be considered to be planned, tangible, large scale for WAS, but small scale for a NSO, ongoing temporally, while spatially it could be international given the tourism aspect. Overall, it is a positive legacy.

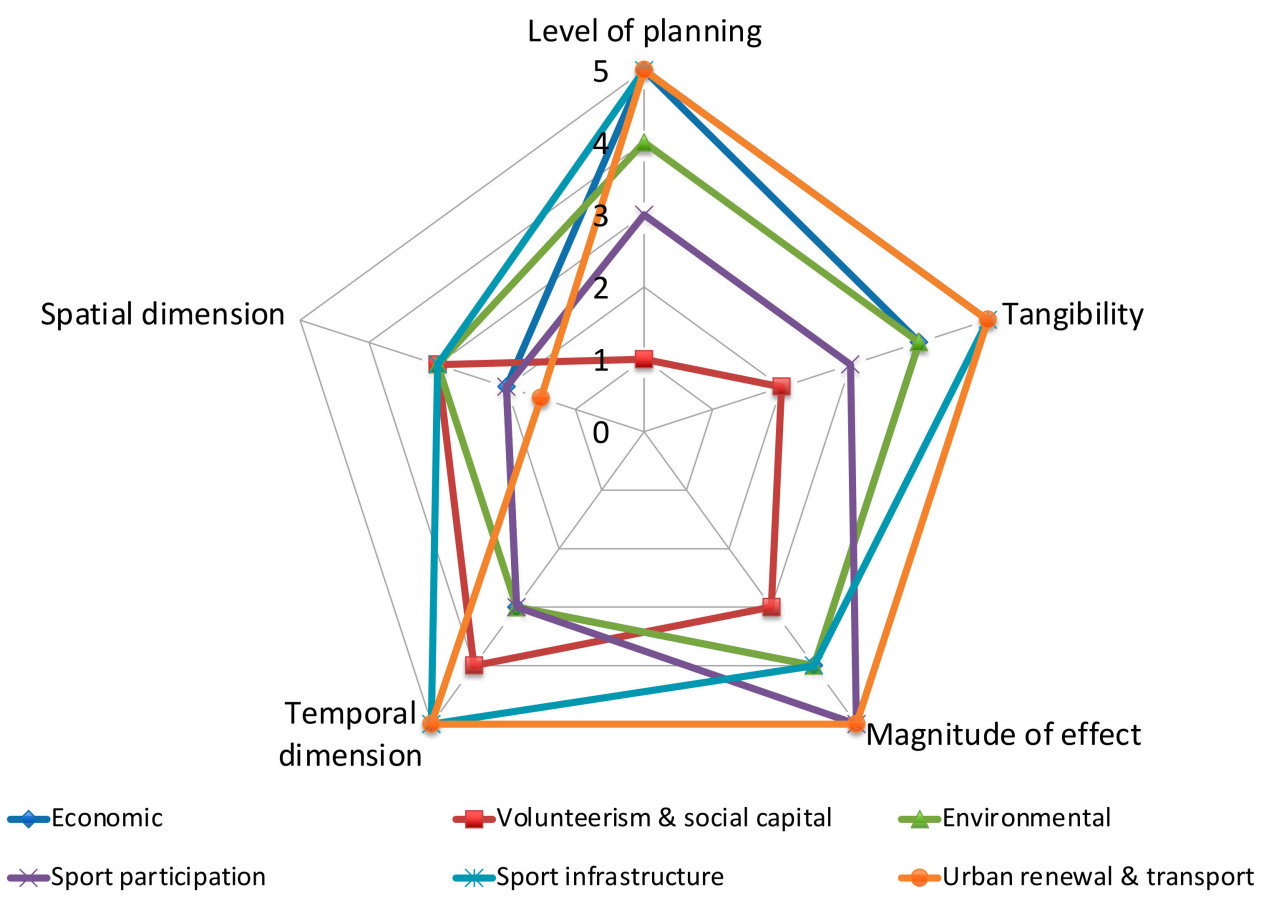

Figure 2. Adaptation of the event legacy radar or web (Dickson et al., 2011).

Realizing legacies requires strategically leveraging the MSE planning, activities, and opportunities across the event's life, from the pre-bid phase through the post-event legacy phase $[25,29]$. However, despite repeated claims that MSE will leave sport participation legacies for host communities, there is little evidence supporting this claim, as most research is not conducted in a period necessary to demonstrate a legacy. Not to say legacy is unachievable, it just has not been demonstrated, yet $[1,2,4,30]$. While, theoretically, this paper draws on the work of Chalip and others (e.g., [20,25,31,32]), significantly this longitudinal research differs by providing empirical evidence that sport participation and tourism legacies are possible, and insight into how this may have occurred in one community.

\subsubsection{Adaptive Sport and Participation Constraints}

Adaptive sports are sport or recreational activities that are modified through equipment, protocols, or rules to enable PwD to participate [33]. In contrast, Paralympic sports are governed by strict classification schemes that aim to promote equal competition between athletes with similar abilities [34]. These narrow classifications mean parasports participation will differ from the broader adaptive sports community. Adaptive sports have been assisted by the provision of various antidiscrimination, disability discrimina- 
tion, and human rights legislation enacted over more than 30 years. The rights enacted within these legislations provide the opportunity for a rich cultural life including sport and tourism [8,35]. These have been further enhanced by the United Nations' [36] Convention for the Rights of Persons with Disabilities (CRPD) which now operates in over 170 nations.

Adaptive sports have evolved to address the participation constraints of PwD, informed by a rich history of examining participation through the constraints framework, including intrapersonal, interpersonal, and structural categorizations, hierarchal approaches, and constraints negotiation $[37,38]$. Constraints research in adaptive sports suggests that PwD have higher levels of constraints than the nondisabled population, and are affected more adversely by compounding structural constraints from community to elite competition $[39,40]$. Recent studies identified the heterogeneous nature of disability and the importance of understanding diverse support needs when considering the typology of constraints to be negotiated through critical disability studies and ableist frameworks [41-43]. Increasingly, authors suggest that mainstream sport could learn from adopting a social approach to understanding disability $[8,44]$ where "disability" is imposed on top of a person's impairment through the disabling-nature of the social, economic, political, and cultural context. Disabling environments are also experienced across the lifespan, including families with young children, the elderly, and those with temporary impairments $[12,45,46]$.

\subsection{The Conceptual Framework for Analysis: Socioecological and Temporal}

To complement MSE legacy and leverage frameworks, sport intervention studies, disability studies' social model, and the leisure constraints framework, this study applies an extension to the socioecological framework (SEF) that explored the multilevel influences upon behavior, thus leveraging human development and behavior research $[15,17,47]$. Bronfenbrenner's latter ecological framework [17] referred to micro, meso, exo, macro, and chrono levels, while in health, the levels were labeled as follows: public policy; community; organizational; interpersonal and intrapersonal [16,47].

SEFs have been applied in various contexts, including sport participation demonstrating the complex interplay of macro, meso, and micro influences on sport participation for different population groups (e.g., [48-50]). However, the chrono or temporal dimension of the SEF is rarely explored [13]. Both temporal and spatial dimensions have been noted as important for event management and legacy research, such as sport participation [7,27,28]. Thus, for this research exploring a MSE legacy and leverage, a novel temporal extension of socioecological framework (TESEF) [13] is applied that reflects the insights from the SEF literature, the episodic nature of events and the temporal dimension of leveraging event legacies, before, during, and after. This additional temporal dimension also reflects models of planned social and organizational change from Lewin, that informed Bronfenbrenner's SEF, that "composed of unfreezing, change of level, and freezing on the new level" [51] (p. 36).

\subsection{Research Question}

To provide insight into our understanding of the temporal nature of legacy and leverage of MSEs for societal benefit the guiding question for this longitudinal case study is, What did Whistler Adaptive Sport do to leverage the Vancouver 2010 Olympic and Paralympic Winter Games to facilitate a sport participation and sport tourism legacy?

\section{Methods}

To explore how MSE legacies may be achieved we analyzed a single prospective longitudinal case study [52]. The case study method aids understanding of complex, situated, social phenomena and enabled the research to retain "the holistic and meaningful characteristics of real-life events" [53] (p. 4). An advantage of a prospective longitudinal case study conducted in real-time is that it ameliorates the limitation of most retrospective research that seeks to determine cause and effect from memory and the reconstruction of events [54]. Multiple data sources are analyzed via the lens of the TESEF to investigate this single, holistic case to add to the literature on sport, events, legacies, and inclusion. The 
case study was developed based on data collected for over a decade, before, during, and post-event. The multiple data sources used for this research reflect the multiple layers of the TESEF and the emergent nature of this research and included: (a) unstructured and semistructured interviews [55-60], (b) documentary analysis (e.g., [61-68]), (c) online media analysis, and (d) event observation (Table 1). The questions for the 2010 semistructured interview drew upon the interview schedule for research on knowledge management and organizational planning for Vancouver2010 legacies [69].

Table 1. Data sources.

\begin{tabular}{|c|c|}
\hline Socioecological Layers & Data Sources \\
\hline Policy & Existing and emerging legislation $[5,70,71]$ \\
\hline Organizational & $\begin{array}{c}\text { Unstructured interviews [55,57-60] } \\
\text { Semistructured interview [56] } \\
\text { WAS website (http:/ / whistleradaptive.com) }\end{array}$ \\
\hline Community & Documents and articles $[45,46,72-76]$ \\
\hline Interpersonal & $\begin{array}{c}\text { Event observation; } \\
\text { articles [76,77]; } \\
\text { WAS website (http:// whistleradaptive.com), } \\
\text { Facebook page post and comments (September 2013-November 2017) } \\
\text { (https:/ / www.facebook.com/WhistlerAdaptiveSportsProgram/) }\end{array}$ \\
\hline Individual & $\begin{array}{l}\text { WAS website (http:/ / whistleradaptive.com), } \\
\text { Facebook page post and comments (September 2013-November 2017) } \\
\text { (https:/ / www.facebook.com/WhistlerAdaptiveSportsProgram/) }\end{array}$ \\
\hline
\end{tabular}

\subsection{Analysis}

Data were transcribed and an inductive method utilizing analytic coding with categorization was undertaken [78]. To facilitate data familiarization an initial reading of the data was conducted, that supported the preliminary analysis, organization, and display of information within legacy, leverage, and the context of the TESEF. The initial round of open coding enabled identification of recurring themes and common conceptual groupings [79]. Additional coding was conducted on the emerging thematic groupings to allow for further categorization of the data to expose core thematic categories and any interrelationships.

\subsection{Research Context}

Context matters, especially for case studies [80]. WAS is located in Whistler which is $125 \mathrm{~km}$ north of Vancouver in the province of British Columbia [81] and was the Host Mountain Resort for Vancouver2010 [72]. Whistler emerged as a ski destination in the 1960s with the Resort Municipality of Whistler (RMOW) being incorporated in 1975. It has since grown to be a year-round international destination with around 3 million visitors annually [82]. Whistler's Olympic story dates back to lobbying of the provincial government by local businessmen to bid for the 1968 Winter Olympics [75]. Further unsuccessful bids were made for the 1972, 1976, and 1980 games, before the successful Vancouver2010 bid [83].

\section{Results}

Following, the case study results and insights were analyzed across the TESEF's five levels and the temporal dimensions relevant for legacy and leveraging for the sport participation and tourism outcomes, beginning with the case study's policy/macro environment.

\subsection{Macro Level: Public Policy}

The adaptive sport policy environment in which this case is situated is quite diverse as sport and disability reside across several portfolio areas like health, urban planning, transport, and recreation [47]. To achieve sport participation legacy requires planning systems that include accessibility provisions, disability discrimination legislation to challenge 
discriminatory practices, and supporting procedures and protocols [84]. These are not static and may evolve across the study period.

\subsubsection{Policy Framework: International, Federal, and Provincial}

When Canada won the bid in 2003, there was no facilitating legislation, provincially or federally, that promoted the participation of PwD in Canadian society, nor sport, recreation, or employment. Three years later the Federal Policy on Sport for Persons with a Disability was launched [85]. Reflecting both Darcy (2003) [84] and the constraints framework, the situated nature of PwD's sport participation barriers were then identified as, values, structures, and "built environments" of society. Building designs, roads, sidewalks, transportation, people's attitudes, institutional policies, and other systems and behaviors interact with each other to create multiple obstacles that prevent persons with a disability from fully participating in sport. These and other barriers impose lifetime limitations on sport participation [85].

In 2010 Canada ratified the 2006 UN Convention on the Rights of Persons with Disabilities on the eve of the Paralympics [86]. Then the Province of British Columbia developed an accessibility strategy $[87,88]$, followed by the Canadian federal government beginning to develop the Canadians with Disabilities Act (CDA) noting that, "Canadians, communities and workplaces benefit when everyone can participate equally in everyday life. There has been much progress in making our society more inclusive, but we can do better" [71]. The CDA is not a direct outcome of Vancouver2010 but, as with other games cities such as Sydney2000, there may have been an acceleration of inclusion policies.

The Federal consultation built upon a 2012 Senate report that identified that only 3\% of Canadian children who identify as having a disability participated in regular organized physical activity compared to $36 \%$ of nondisabled children [89]. Constraints and barriers to their sport participation were a lack of accessible facilities, programs, and trained coaches, as well as information and research to support $\mathrm{PwD}$ to be active. Further, $\mathrm{PwD}$ incurred greater costs for equipment and transport [89]. A Federal act was finally enacted on 21 June 2019 [90].

Additionally, in the post-event period, was the emergence of the UN Sustainable Development Goals (SDG) [91]. Of relevance for this case is the focus on people to enable everyone to achieve their potential "in dignity and equality and in a healthy environment" [91] (p. 3).

Thus, at the time of Vancouver2010 there was a confluence of provincial, national and international influences, both theoretically (leisure barriers and constraints) and practically through inadequate environmental planning, antidiscrimination, and other facilitating policies.

\subsubsection{The Auspicing Body: International Paralympic Committee (IPC)}

Under this policy framework, the IPC's Paralympic legacy objectives before Vancouver2010, addressed some of the barriers previously identified [85,89], and that correlate with UN's CRPD and SDG [36,91], e.g.,

- Accessible infrastructure in sport facilities and overall urban development.

- Development of sport structures/organizations for $\mathrm{PwD}$, from grassroots to elite level.

- Attitudinal changes in the perception of the position and the capabilities of persons with a disability as well as in the self-esteem of the PwD.

- Opportunities for PwD to become fully integrated in social living and to reach their full potential in aspects of life beyond sports [5].

The IPC would support these legacies by applying its resources, expertise, and international networks to advise and facilitate the transfer of good practices to maximize the legacy potential, while acknowledging that "It is also probable that sporting organizations and other agencies representing PwD in the host city/region or country are willing to undertake actions towards legacy" [5] (p. 30). Thus the onus for legacy remained with the OCOG and the host National Paralympic Committee (NPC), "The OCOG shall coordinate such activities to ensure maximization of outcomes, in close co-operation with the Host NPC" [5] (p. 30). Further, the host city and OCOG were responsible to set host community 
legacy objectives and, hence leverage, from the bid phase and "throughout the planning and preparation phase and at Games time" [5]. Notably, post-event activities are not mentioned here.

3.1.3. The Enabling Body: The Vancouver Organizing Committee for the 2010 Olympic and Paralympic Winter Games (VANOC)

The six planning phases for Vancouver2010 discussed in the Business Plan [92] reflect the temporal dimension of leveraging for legacy: (i) Foundation planning/organization building (2003-2005); (ii) Strategic planning (2005-2006); (iii) Overall concept and detailed operational planning (2007-2008); (iv) Games readiness (2008-2009), (v) Games time (January-March 2010); (vi) Wind-up and dissolution (2010). In terms of the TESEF, phases $\mathrm{i}$-iv occurred in the pre-Games period, then the Games period (v), and the wrap-up phase is in the post-Games period (vi) though it only considered a few months post-Vancouver2010.

For VANOC, sustainable community and accessibility legacies were central to the bid:

"The central theme of bidding for and hosting [Vancouver2010] is to create sustainable legacies... VANOC's goal is to leave legacies-physical and humanthat will last long after the final medal of the Games is awarded .... Increased awareness of Paralympic sport and athletes ... Creation of barrier-free access to sport and community facilities" [92] (pp. 34-35).

The athletes' village, particularly, was an opportunity to develop a much-needed accessible infrastructure legacy that begins to address the barriers of transport and the built environment [85] and that could facilitate an adaptive sport participation and adaptive sport tourism, and sport event tourism legacy:

"the village's legacy would be non-market housing, and 216 permanent rooms ( ... 50 percent would be ... completely accessible ... ), for athletes to train and to support the hosting of future World Cup events following the Games". [93] (p. 7)

The legacy was to be underpinned by disability awareness training prior to Vancouver 2010 that addressed barriers of the communities' values, attitudes, and behaviors [85],

"Disability awareness training is key to effective and comfortable interaction with PwD and this opportunity will be provided to all paid staff, volunteers, and security personnel involved with the Vancouver OCOG. Disability awareness training has already been provided to all staff and volunteers involved with the ... Bid Corporation" [81] (p. 181).

Thus, together the urban design, the accessible infrastructure legacy, and the training of volunteers and staff, laid the groundwork upon which an adaptive sport legacy could be built that would address identified barriers and constraints $[85,89]$ and support future sport participation and destination competitiveness legacies [7].

\subsection{Meso Level: Community of Whistler}

Community includes structural factors like physical infrastructure, accessibility, transport, and socioeconomic factors [49]. The Whistler community has a base population of 13,500 , expanding to 50,000 during peak periods, the RMOW limits population growth to maintain community and environmental sustainability which is relevant for sport development opportunities [75]. Resort development during this period was under earlier Building Standards that focused more on the needs of people with temporary disabilities rather than contemporary understandings of access-for-all (e.g., [12,45,77,94,95]).

In line with the IPC's guidelines [5], in 2002 the bid committee approached WAS to help plan for a Paralympic legacy with particular interest in community sport organizations that could deliver on a vision for adaptive sport nationally and internationally [45]. Key elements were programs, training venues, temporary accommodation, and affordable housing strategies. By 2003, Whistler's accessibility vision included urban planning, transport and venues: 
a highly accessible pedestrian-oriented village ... offers excellent services for PwD ... by 2010 Whistler's public transit system should be $100 \%$ accessible. All venues built ... will meet or exceed the provincial or national building code accessibility requirements. Funds have been dedicated in the Vancouver OCOG budget specifically for accessibility enhancements for all new venues [81] (p. 5).

In 2006, the bid corporation's vision was reflected in the Municipality's Vancouver2010 Strategic Framework that outlined 20 legacies, including accessibility, sport participation, and enhancements to WAS [72]. These depended upon facilitating urban design, transport, and housing. The bid committee's vision was also instrumental in guiding the RMOW's broader sustainability vision, "Along with creating lasting legacies [Vancouver2010] also brought accessibility to the forefront of Whistlerites' consciousness. Emphasis has been placed on meeting the needs of all ages and abilities" [75] (p. 28). Accessible was defined as "free of barriers, open to all" [75] (p. 63), with KPIs reflecting the IPC's legacy objectives, where the built environment is "safe and accessible for people of all abilities, anticipating and accommodating wellbeing needs and satisfying visitor expectations" (p. 47). Recreation is accessible year-round for "Residents and visitors of all ages and abilities ... that encourages health living, learning and a sense of community" (p. 56). This sense of community is considered a contributing factor towards legacy success [59]. Accessible transportation systems "to, from and within the resort community ... offer affordable travel options" (p. 59) are supported by accessible communication and services across the visitor's journey. Whistler's accessibility journey continues into 2020 and beyond as they align with still emerging policies and practice [46].

\subsubsection{Meso Level: Organization-Whistler Adaptive Sports}

Organizational factors include the community's sport club environment and schools [50]. In this case, the organization that filled the role of a community sport club was WAS, a not-for-profit society, commenced in 1999, to provide,

year-around, recreational programs for people of all ages with disabilities ... a centre for learning and sports excellence that has a local, regional, national and international clientele and encourage independence, self-confidence and self-motivation for all of our athletes and participants through outdoor recreation (http:/ / www.whistleradaptive.com).

In line with this vision, WAS has evolved from primarily a snowsport organization (i.e., skiing and snowboarding) to a multisport, year-round, organization offering services to participants from one-off participation, instruction, competition, and coaching across 16 summer and winter sports [56]. Sports include: hiking, biking, canoeing, rowing, skiing, snowboarding, yoga, climbing, biathlon, stand up paddle boarding, and adaptive mountain biking [60] reflecting Whistler's ongoing evolution as a world-class year-round destination. Participation growth has been in both the number of participants and also the number of days per participant, thus there has been both a sport participation and a sport development legacy [30]. Part of WAS's evolving vision is that by 2022 there will be a Canadian Paralympian competing in Beijing who has passed through WAS [58].

WAS caters predominately for PwD with cognitive and/or mobility impairment across all levels of participation, effectively reaching PwD in their local community of Whistler and Pemberton. Since 2017 this has expanded to providing volunteer services to the neighboring community of Squamish, including up to $120 \mathrm{~h}$ of support for 30-40 children, allowing families a few hours of respite while their children participate in sport, recreation, and physical activities [76]. PwD from outside the Whistler region also travel for adaptive sport and sport event opportunities, accounting for $90 \%$ of individuals in WAS programs [64]. This adaptive sport tourism element distinguishes WAS from most single sport parasport organizations or single disability service organizations.

It is evident that there has been exponential growth in the participation in WAS programs with over a $600 \%$ increase in participation/lessons since Vancouver2010 (Figure 1). 
In contrast, mainstream sport and physical activity research did not reveal any significant increase in participation legacy from Vancouver2010 [2,96]. WAS activities are supported by 180 volunteers mostly in winter $(n=120)$ who have previously contributed c.25,000 volunteer hours across $2800+$ lessons/activity days, or c. $140 \mathrm{~h}$ per volunteer [55]. A winter volunteer who gives 23 days ( 3 days training and 20 days volunteering) receives a free season's lift pass negotiated as in-kind support by WAS (CAD979 for 2020/21). Participation growth was further facilitated by the opening in 2011 of the first American Disability Act compliant building in Whistler, which is also WAS's winter on-mountain base [73]. Their vision was to use this facility to support summer mountain biking [57] thus facilitating sustainable year-round adaptive sport tourism.

\subsubsection{Changing Perceptions of Relationship with PSOs and NSOs}

Before Vancouver2010, the perception of WAS's relationship with provincial sporting organizations (PSO) and national sporting organizations (NSOs) was a typical bureaucratic design (Figure 3). This, in part, would reflect their snowsports history, but not their emerging multisport offerings across summer and winter, nor activities where there are no $\mathrm{NSO}$ /PSO, such as hiking. However, traditional PSO/NSO instructor/coach sport credentialing does not recognize multisport volunteers and staff, adding to the costs to maintain official credentials and memberships that enable access to sport-specific insurances [57], undermining sustainable growth.

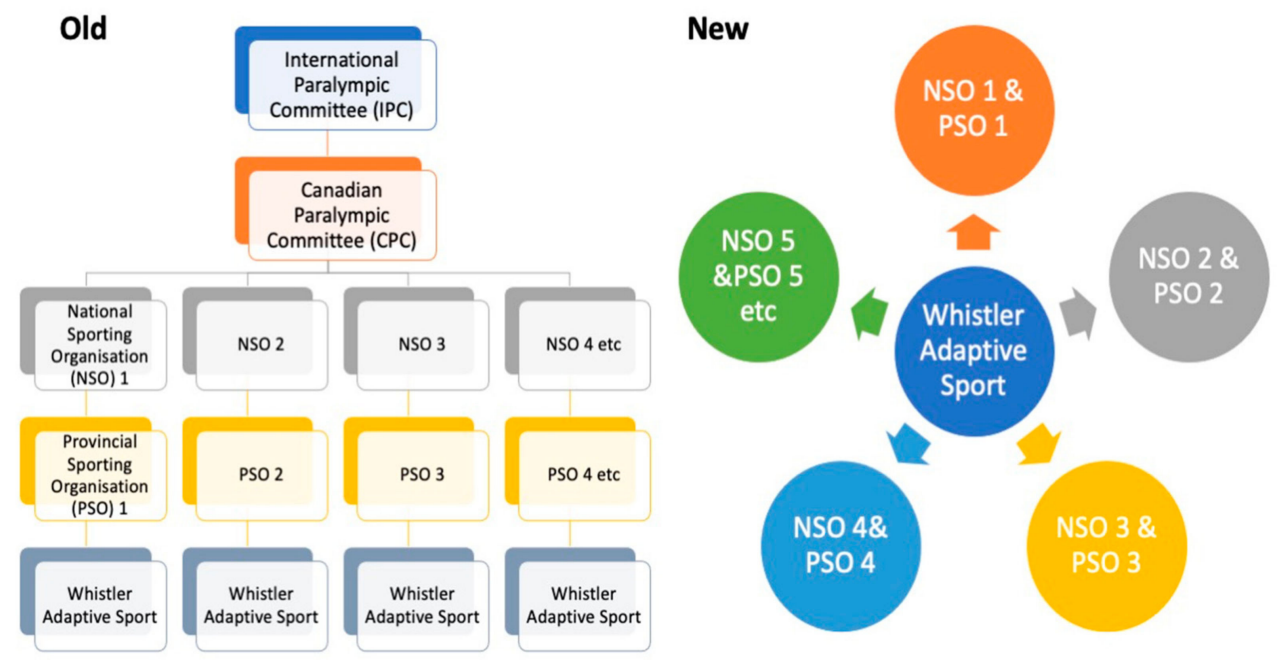

Figure 3. Old and new models of sport systems (Walker, 2012).

Post-event, with changes in sport offerings, and more athletes, volunteers, and lessons, the perceptions of how WAS related to the NSOs/PSOs and other sporting bodies had to move from the traditional silo/hierarchical sport model to a more organic model that allows growth as the market (i.e., the community) demands, more of a wheel-and-spoke (Figure 3). This change in thinking also applies to training volunteers who often work across multiple sports, "Whenever I train a volunteer I want a universal skill set" [57].

\subsubsection{Broadening Vision and Leadership}

WAS's growth paralleled its shift to a multisport organization and reflected changing community needs. The increasing complexity of offerings and vision needed innovation and social entrepreneurial leadership. In 2005, Chelsey Walker was appointed as the first Executive Director (ED). Walker came from an alpine ski racing, heli-ski guiding and sport development background [57,77], but did not have any connection with WAS nor disability sport or services prior to commencing with WAS. Walker's job included "to come in and create partnerships" [77] (p. 47). 


\subsubsection{Pre-Event: Strategic Planning for the Future: 4 Pillars}

Five years pre-event, WAS strategically identified four pillars to leverage Vancouver2010 [56],

1. Volunteer and staffing: WAS worked with VANOC to place volunteers in test events to gain experience. Most of the 160 games-time volunteers were from WAS, those who did not have a prior connection to WAS were encouraged to join. To keep volunteers engaged post-games the key was "to steward our volunteers" [56]. As Whistler has a highly transient population ongoing recruitment and training of new volunteers is required.

2. Marketing and media: "To keep the interest in Paralympics sports we need to continue to attract high level sports" [56]. Thus, a strategic plan was developed to attract future events beyond 2010 to facilitate brand-awareness and sponsorship attractiveness [55]. WAS's success in raising their brand and product awareness is reflected in not needing to advertise to attract more clients as demand growth outpaces their ability to supply due to volunteer and equipment resource limits, resulting in waitlists for lessons [60].

3. Infrastructure. Linked to the fully accessible public transport system by the time of Vancouver2010 and the Athletes' Village design with 40\% accessible rooms and 25\% with wheel-in showers, post-event WAS had a free office for at least 5 years, and access to accessible accommodation to support training and adaptive sport tourism $[55,97]$.

4. Funding to enhance programming. Leveraging awareness that investment in parasports is a whole-of-life investment which can decrease health costs for parasports participants underpins knowing your political advantage. This required WAS to develop efficiencies: "cross-pollination for volunteers and resources, e.g., mountain biking and Nordic uses the same timing systems" [56]. Further knowing your competitive advantage is essential: "For sport tourism we focused on what we do well, wintersports, outdoor aerobic (mountain biking, running), parasports" [56].

Shortly after Vancouver2010, of over 30 volunteer organizations surveyed about legacy strategies, WAS was the only one to have a plan, and the only one to achieve their desired legacy [69]. This highlights the need to work with key stakeholders prior to an event to identify, implement, and monitor organizational and community relevant leveraging strategies.

\subsubsection{Post-Event: Product Innovation, Partnerships, and Sponsorships}

In the post-event era, innovation and partnership were key themes in line with Walker's job requirements [77]. New partnerships were developed with the community; commercial/sponsors and sporting organizations, while existing partnerships evolved such as integrating Para and Special Olympic athletes (predominantly intellectual and cognitive disability) into the mainstream Whistler Race Club for skiing and snowboarding. In addition to the growth in lessons and volunteers, there has been an increased brand awareness that helped with signing a 5-year sponsorship agreement 2011-2015 worth CAD 535,000 that complemented the sponsor pool and offset losing the Scotiabank sponsorship before Vancouver2010, reportedly as a direct consequence of the 2008 Global Financial Crisis (GFC) [61].

In 2012 a new product was offered, a Girls Summer Multisport Camp. This three-day camp for up to 10 participants aged $13-25$ with both physical and cognitive disabilities who wanted to try either a new sport or expand their repertoire of activities. Seven attended, participating in biking, kayaking (white water and sprint boats), canoeing, rowing, and yoga. This program was facilitated by new partnerships (e.g., with Canoe Kayak BC, a PSO) that provided grants, personnel (coaches), and equipment (canoes). Camps, rather than drop-in lessons, have also been central to their recent growth strategy for adaptive mountain biking [98]. 


\subsection{Micro Level}

\subsubsection{Interpersonal Factors}

Interpersonal factors include the support of friends and family [50]. For PwD, support is even more important depending upon the disability-type and level of support required and is inextricably linked to PwD's sport participation [41]. Support includes volunteers, training and also families, carers, and paid attendants. The centrality of support of volunteers, coaches, families, and friends is reflected in many of the quotes analyzed in the following section. Sharing of their voices is also a reminder of why this work is important.

\subsubsection{Individual/Participants}

As an organization that seeks to meets the needs of its athletes, both within and beyond Whistler, WAS works more like a sports or community centre than a sports club [57]. Each individual may be interested in participating across a range of activities during their years of involvement, or career-path, with WAS. Having multiskilled volunteers and a range of resources and partnerships can help support the athletes' journeys.

Athletes are not just viewed as recipients of services, but as future providers of services as volunteers and coaches [63]. To this end, the organization has strategic plans for training, mentoring, and empowering individuals to progress through to positions of responsibility whether they have disabilities or not. Each person participating with WAS has their own unique requirements depending upon their disability type and support needs requiring individual negotiation for sport or volunteer participation [41].

To hear the voices of those who have benefited, 121 unsolicited posts to the public WAS Facebook page about their adapted sport experiences during the period September 2013November 2017 were analyzed. Of the responses 37 were from participants, families, or volunteers. Relatively few discussed specific barriers they faced $(\mathrm{N}=7)$, identifying unique intrapersonal challenges, interpersonal issues, and structural constraints. All 37 discussed the facilitators that WAS provided and the outcomes they achieved. Three participants commented on their acquired disability and the profound life changing opportunities WAS provides with relatively simple adaptations for their individual needs.

"I was canoeing \& skiing before June 2016, when I suffered a stroke. Overnight I could not do anything. Now I have an adaptive paddle so I can canoe again-not well but I am on the water. I have learned to swim with one arm. Now I want to ski again" (FB\#1).

For parents with a child with a congenital disability, it was with the bitter taste of discrimination in other programs that led to their sport tourism opportunity with WAS.

"At first, I was disappointed when I was told that my special need son cannot be in the regular ski school and have to be in the adaptive program. I was totally blown away with the Adaptive program that is specially designed for people like him. He enjoyed every bit of it and still talks about the ski trip after a month of being home. The staff as well as the volunteers were so nice, accommodating, and most of all, I am surprised with everything that he has learn in just the 3 days we were there" (FB\#2).

While other participants noted negative attitudes towards PwD from other sport organizations, other structural constraints affected their opportunity for engagement including financial constraints, access to adaptive equipment and trail accessibility. The facilitators were access to adaptive equipment $(37 \%)$, adapted programs $(30 \%)$, but overwhelmingly most comments were about the support offered by WAS staff, volunteers, or coaches $(45 \%)$, providing opportunities for great experiences from recreation to elite sport,

"thank you so much!... I am so deeply grateful for your time and energy. Thanks to the great work you are doing helping more youth enjoy the satisfaction of participating in sport" (FB\#71). 
"it was 2 years ago today that after 10 years of lobbying for, and participating in adapted snowboarding, we competed at the Paralympic games. I am so proud to be a part of it! Thank you for all your support" (FB\#84).

Other participants who were tourists noted that WAS, with their enhanced offerings and increased volunteer base post-Vancouver2010, had become part of their lives by keeping all members of their family and friendship groups doing the same activity, overcoming interpersonal constraints also experienced by potential able-bodied skiers and snowboarders [99].

"We made an early season trip to the mountain in a fit of spontaneity. It was 5 of what will be 6 trips in 5 years. One of the primary things that keeps our merry band coming back is that WASP reinvigorated our brother and pal ... in terms of skiing. He's taken to enjoying it so much, and our whole group of family/friends look forward to bonding together on the hill. We bumped into his very first instructor (the ReMotivator!) ... and caught sight of two other instructors we've had over 5 years. This all speaks to the consistency of good and skilled people you have there, and why you have at least one returning learner every year. Thanks so much for all you do. All of you" (FB\#106).

Some participants recognized that WAS's efforts are complex and require a professional group of staff and volunteers to provide both an experience in the outdoors but also raise funds to support a very expensive operation,

"Thank you ... for seeing a need here and help push for grants for these bikes. I think we're onto something and without all of you this weekend wouldn't have been possible. It takes a cohesive, loving, adventurous group to make things run smooth and you nailed it!" (FB\#25).

The outcomes of an activity provided a focus for individuals who otherwise wouldn't have had the experience and the activity becomes part of their lives to the point of one person stating that the program and WAS was "my happy place". (FB\#85)

\subsection{Temporal Extension of the Socioecological Framework (TESEF)}

The findings are brought together in the TESEF that helps the reader picture the complex, temporal, and situated nature of leveraging for MSE legacy across the different layers involving the diversity of stakeholders (Figure 4). The importance of complexity, temporality, spatiality, and the contextualized nature of MSE legacy are explored further in the discussion. 


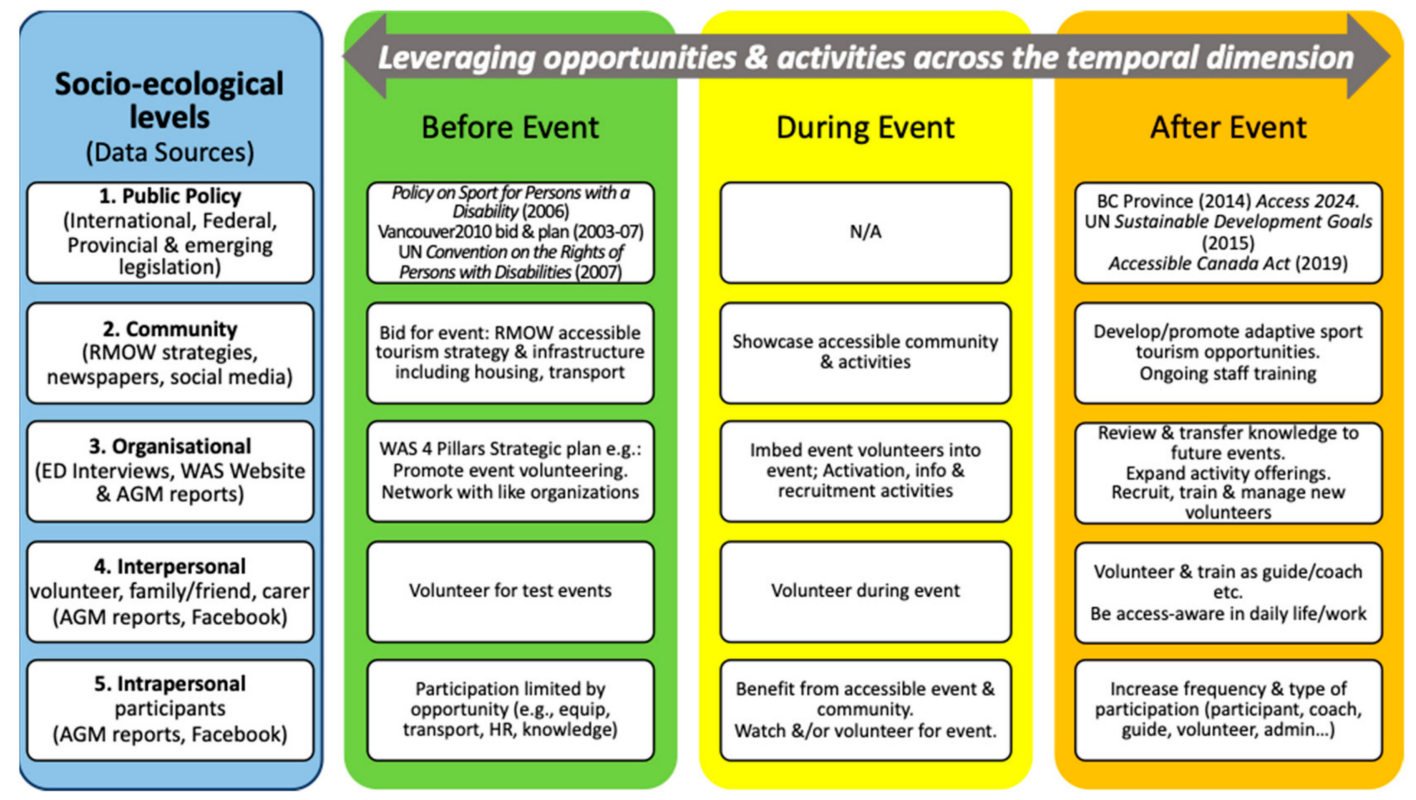

Figure 4. Application of the temporal extension of the socioecological framework (TESEF).

\section{Discussion}

In response to the research question, the findings provide insight into how WAS leveraged a sport participation legacy within the complex, multilevel environment surrounding Vancouver2010. The following discussion addresses the six key areas that add to the theoretical, methodological, and management understanding of MSE legacy and leveraging across a decade in the life of WAS.

First, theoretically this paper drew upon work in event legacy and leveraging; and adaptive sports and inclusion. Adding the socioecological framework allows for a more nuanced understanding of MSE legacy and leverage of Vancouver2010. By incorporating Vancouver2010's sociocultural context, VANOC's legacy and accessibility agenda, and the milieu of factors that led to WAS's success, enhances our understanding of MSE legacy and leverage theory. The TESEF provides a mechanism to understand the whole system changes across the levels of individual; interpersonal; organizational; community and macro policy environments. The complexity demonstrated here is firstly a function of the numerous stakeholders within and across all levels in the leveraging and legacy process starting with how marginalized identities, in this case starting with elite parasport athletes, were included across all levels of the framework [14]. While Vancouver2010 started with the elite Paralympians, WAS always focused on including adaptive opportunities for all [12]. Other stakeholders in this context included the MSE auspicing, funding, and organizing bodies (e.g., IPC, Federal and provincial governments, VANOC); host communities and local government (e.g., Whistler and RMOW); sport organizations and supporters (e.g., WAS, their staff, volunteers, and sponsors); then those most likely to benefit, the individual participants, their friends, and families. These are situated within an immature Canadian macro policy environment whose sophistication evolved over the decade post-2010 through provincial and national legislation $[70,71,90]$, together with an expanded understanding of Olympic and Paralympic legacy that may be applied to future events $[6,69]$.

Second, methodologically this has been the first prospective longitudinal case study exploring MSE legacies with the clear integration of a temporal dimension. While previous MSE research has examined legacy, most have done so through ad hoc approaches and rarely long after the event. Most legacy papers are pre-event hypothesizing or theorizing on legacy with few after the event (e.g., [7,19-21]) and almost none consider around a decade post-event. Yet, there is a clear temporal dimension of MSE, leveraging and legacy: from bid processes beginning a decade or more before; bid awarding, through to the 
design/development phase; the intense ramp up in OCOG activities in the year before the event; and legacies potentially lasting for a decade or more beyond the event [27]. Temporality is not just duration, but also the time limits imposed by the MSE. While this research demonstrates the value of the TESEF where there is a defined 'intervention' or event. Unlike physical activity interventions, MSE OCOGs have time constraints if hosts are to leverage for legacies, with OCOGs having 'sunset clauses' limiting their ability to leverage far beyond the event [24,25]. Vancouver2010 provided WAS and its stakeholders a once-in-a-life-time opportunity, with unique volunteering experiences, media exposure to raise awareness of WAS and adaptive sports, and infrastructure legacies of office space and accessible accommodation and training facilities. Thus, through the TESEF lens a more nuanced understanding emerges of the complex, and contextualized, interplay between participant, organizational, community, national, and international barriers and facilitators over the extended time-period better reflecting the temporal nature of social and organizational change processes [51].

Third, in contrast to previous research $[1,2,4,30,97]$, WAS clearly, and strategically, facilitated a sport participation and sport tourism legacy from Vancouver2010 that was inextricably linked to their leveraging strategies before, during, and after the event, within the context of an evolving policy and social environment (Figure 4). Through the TESEF, this research followed the staged development of the complex MSE environment for adaptive sport in Whistler, from a winter-sport focus to a multisport and multivenue delivery and to more community-focused sport offerings. This research followed WAS's strategic change, together with a detailed understanding of the barriers and facilitators to WAS's sport participation legacy as demonstrated by the exponential growth in participation across the study period (Figure 1). International, federal, and provincial human rights, sport and disability policies (macro) dovetailed with local policies and strategies (meso) to create a 'perfect storm' for legacy and leverage aligned to WAS's strategic purposes. However, policies alone do not lead to legacy, they need to be supported by facilitators reflecting a community and organization's visions and desires that parallel a MSE legacy and leverage aims [100]. From this case, the importance of researchers' pragmatic engagement, over the life-course of the research, is highlighted when drawing upon natural data from interpersonal, meso management information systems, and social media sources. The sport participation system transformation observed here did not occur by happenstance and leads onto the next two points (Figure 4).

Fourth, WAS's transformation was under the leadership of a charismatic and innovative ED following a new social entrepreneurial pathway [101]. That pathway required a vision from the Board and the ED for a future that challenged sport traditions. It did so through transforming from a winter-emphasis to a year-round focus reflective of Whistler as a year-round international tourism destination [82]. Change is not without organizational risk particularly highlighted by challenges to sport and tourism brought about by external shocks such as the GFC and COVID-19. The noted challenges for the predominantly volunteer workforce of year-round provision, together with the introduction of new sports also challenged the organization from a retention, credentialing, coaching, and equipment provision basis. The combination of mountain and water-based activities also adds new risk-profiles and equipment maintenance and storage considerations.

Fifth, WAS recognizes the legacy of networked accessible infrastructure across Whistler (e.g., transport linkages, accommodation, and food and beverage) that provided PwD a mostly inclusive destination [7]. This accessibility extends from the village to accessing the natural environment required for new sporting opportunities. Yet, without the strategic leveraging of the volunteer resources, the increase in sport participation opportunities would not have been possible. The ED and Board $[56,65]$ recognize the summer and winter sport and event tourism opportunities that leverage off the accessible infrastructure legacies and increased volunteer resources [7]. As noted in the findings, there was an increase in activity across both winter and summer seasons, benefiting from the competitive advantage of accessible accommodation offerings and volunteer support. The new activities, 
while stretching the volunteer workforce, also introduced WAS to new stakeholders in summer, expanding their in-kind and sponsorship-based opportunities. This allowed WAS to increase its funding base, diversifying the risk and addressing some of the resource challenges it faced to remain sustainable [65]. In turn, the community saw mutual benefit through increased summer visitation for PwD who are challenged by a series of structural constraints through providing an accessible destination and subsidized adaptive sporting activities, thus facilitating the spatial dimension of legacy. This sport tourism component also provided opportunities for family and friendship groups to be involved in the same activities enhancing participation by $\mathrm{PwD}$ with dignity and equity. As the Facebook quotes suggested, this was the first time for many to holiday and be involved in these activities as a family group with the PwD.

Sixth, what also emerges from this case study is the importance of the social and environmental context, i.e., legacy and leveraging theory and practice should not be decontextualized. WAS is part of, and embedded within, a close-knit community [59]. In part, WAS is successful because of the geographic location, both in terms of the healthy interplay of natural and built recreational opportunities but also proximity to other growing markets where their products and services could grow, such as Pemberton, Squamish, and Vancouver, enabling economic sustainability. Further, the importance of sport tourism, including accessible tourism, to Whistler (e.g., [45,46,75]) enables visitors to the area to benefit from the growing array of sports products and services which may support the development of new products and services that residents could benefit from, thus further leveraging from the Vancouver2010 legacy through enhancing their destination competitiveness for the benefit of residents and visitors alike [7].

\subsection{Challenges for the Future}

More than a decade since the four pillars were established, a major challenge for WAS is how to continue to grow beyond the leveraging opportunities of Vancouver2010 [66]. At the community level, Whistler, has to consider how to sustainably grow as a sport tourism destination, a space that is increasingly competitive as other destinations in British Columbia seek to benefit from sport and event tourism strategies [102,103]. In 2020 the RMOW reaffirmed their commitment to accessibility and also a need to align to the new national Accessible Canada Act (2019) (ACA) and address targets not yet achieved, such as accessible transport [46]. The ACA does not provide for retrospective accessibility unless changes in use to a building or environment are required. While there may be an expectation that the act will bring immediate improvements, this belies the reality of the act that requires strategic prioritization of accessibility improvements for sport participation. Financially, Canada is highly dependent upon resources and tourism, thus negotiation of future commercial partnerships and sponsorships will be influenced by external economic factors, which at the time of writing included the impacts of external shocks such as COVID-19. Socially, WAS is dependent upon volunteer contributions, but from a transient population base, thus it is demanding for those that remain to maintain the culture and standards when you have a potentially high staff turnover. For the last decade one constant has been the ED, but an organization looking to grow cannot depend upon a single leader indefinitely [66].

\subsection{Study Limitations}

Some of the limitations of conducting a prospective longitudinal case study of MSE legacy over a period of more than a decade is that initially it is not always possible to identify whether there will be a legacy to research. If there is a legacy, identifying those organizations that may plan for strategic goals and outcomes is also problematic. Hence, knowing where the data may be obtained from across the life of the research requires a pragmatic, flexible, and emergent research design that is difficult to articulate in funding applications for prospective research. The research design and data collection methods have to evolve to reflect the changing real-world context such as the use of websites and 
Facebook which, at the commencement of the project, were not even key communication methods for WAS. Further interviews, personal communication, and social media posts with organizational insiders may overemphasize the positive by those associated with the activities, but this can also be balanced by social media increasingly being a safe space for people to share their complaints and concerns. While the TESEF facilitates understanding of the layers and sequence of activities, it does not quantify the influence of each on the final outcome.

\section{Conclusions}

This paper highlights the complex, temporal, and contextualized nature of delivering a socially, environmentally, and economically sustainable MSE sport tourism and participation legacy for a community-level organization. Through the lens of the novel TESEF this research highlights the temporal and multilevel requirements for leveraging off an MSE for legacy beginning in the bid phases and continuing beyond the life of the event and the OCOG. This research demonstrates that having high-level policies for disability, inclusion, and sport participation is not enough to achieve community-level societal outcomes. To achieve real and sustainable outcomes of social change for PwD, macro policies need to be operationalized via local and regional policies, planning and actions in what may be called a mutual or coleveraging scenario.

Using the momentum and opportunities provided by Vancouver2010, WAS's board and ED sought strategic engagements with other sporting organizations, disability organizations, and disability sporting organizations to leverage Vancouver2010 to continue to evolve from a single program, single disability to a highly complex facilitator-organization offering multiple sporting programs within a sport tourism context across the year, to thousands of individuals for many years beyond Vancouver2010. This was achieved on a limited budget, underpinned by sponsorship, fundraising, partnerships, vision, and passion. They have demonstrated that sport participation legacies are achievable from a MSE, but it required policies, strategies, and practices across all levels and temporal phases of the TESEF that reflect their unique sociocultural context.

Author Contributions: Conceptualization, T.J.D., C.W. and S.D.; methodology, S.D. and T.J.D.; validation, T.J.D., S.D. and C.W.; formal analysis, T.J.D. investigation, T.J.D., C.W. and S.D.; data curation, T.D., C.W. and S.D.; writing—original draft preparation, T.J.D. and S.D.; writing—review and editing, T.J.D., S.D. and C.W.; visualization, T.D. All authors have read and agreed to the published version of the manuscript.

Funding: This research received no external funding.

Institutional Review Board Statement: The study was conducted according to the guidelines of the Declaration of Helsinki, and approved by the University of Canberra Committee for Ethics in Human Research (09-88, approved 16th September 2009).

Informed Consent Statement: Informed consent was obtained from all subjects involved in the study. Data Availability Statement: Data sharing not applicable.

Conflicts of Interest: The authors declare no conflict of interest.

\section{References}

1. Weed, M.; Coren, E.; Fiore, J.; Wellard, I.; Chatziefstathiou, D.; Mansfield, L.; Dowse, S. The Olympic Games and raising sport participation: A systematic review of evidence and an interrogation of policy for a demonstration effect. Eur. Sport Manag. $Q$. 2015, 15, 195-226. [CrossRef]

2. Craig, C.L.; Bauman, A.E. The impact of the Vancouver Winter Olympics on population level physical activity and sport participation among Canadian children and adolescents: Population based study. Int. J. Behav. Nutri. Phys. Act. 2014, 11, 107. [CrossRef] [PubMed]

3. Feng, J.; Hong, F. The legacy: Did the Beijing Olympic Games have a long-term impact on grassroots sport participation in Chinese townships? Int. J. His. Sport 2013, 30, 407-421. [CrossRef]

4. Veal, A.J.; Toohey, K.M.; Frawley, S. The sport participation legacy of the Sydney 2000 Olympic Games and other international sporting events hosted in Australia. J. Policy Res. Tour. Leis. Event 2012, 4, 155-184. [CrossRef] 
5. IPC. Section 1 Chapter 3 Paralympic Games Chapter. In IPC Handbook; International Paralympic Committee (IPC): Bonn, Germany, 2007; pp. 1-43.

6. Thompson, W.R.; Vanlandewijck, Y.C. Perspectives on research conducted at the Paralympic Games. Disabil. Rehabil. 2020. [CrossRef] [PubMed]

7. Dickson, T.J.; Misener, L.; Darcy, S. Enhancing destination competitiveness through disability sport event legacies: Developing an interdisciplinary typology. Int. J. Contemp. Hosp. Manag. 2017, 29, 924-946. [CrossRef]

8. Misener, L.; Darcy, S. Managing Disability Sport: From athletes with disabilities to inclusive organisational perspective. Sport Manag. Rev. 2014, 17, 1-7. [CrossRef]

9. Jaarsma, E.; Dijkstra, P.; Geertzen, J.; Dekker, R. Barriers to and facilitators of sports participation for people with physical disabilities: A systematic review. Scand. J. Med. Sci. Sports 2014, 24, 871-881. [CrossRef]

10. Dickson, T.J. How to Apply A Strategic Approach to Delivering Legacies from Hosting Mega Sport Events. Available online: https://www.chrie.org/files/0012018_Dickson.pdf (accessed on 15 July 2019).

11. Whitehead, M. Physical Literacy: Throughout the Lifecourse; Routledge: London, UK, 2010.

12. Darcy, S.; Dickson, T.J. A whole-of-life approach to tourism: The case for accessible tourism experiences. J. Hosp. Tour. Manag. 2009, 16, 24-31. [CrossRef]

13. Dickson, T.J.; Darcy, S. A question of time: A brief systematic review and temporal extension of the socioecological framework as applied in sport and physical activity. Transl. Sport Med. 2020, 1-11. [CrossRef]

14. Henderson, K.A. A paradox of sport management and physical activity interventions. Sport Manag. Rev. 2009, 12, 57-65. [CrossRef]

15. Bronfenbrenner, U. The Ecology of Human Development; Harvard University Press: Cambridge, MA, USA, 1979.

16. Sallis, J.F.; Owen, N. Ecological models of health behavior. In Health Behavior: Theory, Research, and Practice, 5th ed.; Glanz, K., Rimer, B.K., Viswanath, K., Eds.; Jossey-Bass: San Francisco, CA, USA, 2015; pp. 43-64.

17. Bronfenbrenner, U. Ecological Systems Theory; Jessica Kingsley: London, UK, 1992.

18. De Bosscher, V.; De Knop, P.; Van Bottenburg, M.; Shibli, S. A conceptual framework for analysing sports policy factors leading to international sporting success. Eur. Sport. Manag. Q. 2006, 6, 185-215. [CrossRef]

19. Carmichael, F.; Grix, J.; Marqués, D.P. The Olympic legacy and participation in sport: An interim assessment of Sport England's Active People Survey for sports studies research. Int. J. Sport Policy Polit. 2012, 5, 229-244. [CrossRef]

20. Chalip, L.; Green, B.C.; Taks, M.; Misener, L. Creating sport participation from sport events: Making it happen. Int. J. Sport Policy Polit. 2017, 9, 257-276. [CrossRef]

21. Misener, L. Leveraging parasport events for community participation: Development of a theoretical framework. Eur. Sport Manag. Q. 2015, 15, 132-153. [CrossRef]

22. Gillovic, B.; McIntosh, A. Accessibility and Inclusive Tourism Development: Current State and Future Agenda. Sustainability 2020, 12, 9722. [CrossRef]

23. Gillovic, B.; McIntosh, A.; Cockburn-Wootten, C.; Darcy, S. Having a voice in inclusive tourism research. Ann. Tour. Res. 2018, 71, 54-56. [CrossRef]

24. Dickson, T.J.; Darcy, S.; Pentifallo Gadd, C. Ensuring volunteer impact, legacy and leveraging is not "fake news": Lessons from the 2015 FIFA Women's World Cup. Int. J. Contemp. Hosp. Manag. 2020, 32, 683-705. [CrossRef]

25. Chalip, L. From legacy to leverage. In Leveraging Legacies from Sports Mega-Events: Concepts and Cases; Grix, J., Ed.; Springer: Basingstoke, UK, 2014; pp. 2-12.

26. Cashman, R.; Horne, J. Managing Legacy. In Managing the Olympics; Frawley, S., Adair, D., Eds.; Palgrave Macmillan: London, UK, 2013; pp. 50-65. [CrossRef]

27. Dickson, T.J.; Benson, A.M.; Blackman, D.A. Developing a framework for evaluating Olympic and Paralympic legacies. J. Sport Tour. 2011, 16, 285-302. [CrossRef]

28. Misener, L. Managing Legacy and the Paralympic Games. In Managing the Paralympic Games; Darcy, S., Frawley, S., Adair, D., Eds.; Palgrave Macmillan: Basingstoke, UK, 2017.

29. Dickson, T.J.; Terwiel, F.A.; Buick, F. Paralympic Volunteer Management. In Managing the Paralympic Games; Darcy, S., Frawley, S., Adair, D., Eds.; Palgrave Macmillan: Basingstoke, UK, 2017; pp. 193-216.

30. Taks, M.; Green, B.C.; Misener, L.; Chalip, L. Evaluating sport development outcomes: The case of a medium-sized international sport event. Eur. Sport Manag. Q. 2014, 14, 213-237. [CrossRef]

31. Chalip, L. Towards Social Leverage of Sport Events. J. Sport Tour. 2006, 11, 109-127. [CrossRef]

32. Chalip, L. Trading legacy for leverage. In Legacies of Mega Events: Fact or Fairy Tales; Brittain, I., Bocarro, J., Byers, T., Swart, K., Eds.; Routledge: London, UK, 2018; pp. 25-42.

33. Winnick, J.; Porretta, D. (Eds.) Adapted Physical Education and Sport, 6th ed.; Human Kinetics: Champaign, IL, USA, 2016.

34. Darcy, S.; Frawley, S.; Adair, D. The Paralympic Games: Managerial and Strategic Directions. In Managing the Paralympics; Palgrave MacMillan: Basingstoke, UK, 2017; pp. 1-19.

35. McColl, M.A.; Schaub, M.; Sampson, L.; Hong, K. A Canadians with Disabilities Act? Available online: http://www.ccdonline. $\mathrm{ca} / \mathrm{en} /$ socialpolicy/fda/cda (accessed on 7 September 2020).

36. UN. Convention on the Rights of Persons with Disabilities; United Nations (UN) General Assembly A/61/611: New York, NY, USA, 2006.

37. Jackson, E.L.; Crawford, D.W.; Godbey, G. Negotiation of leisure constraints. Leis. Sci. 1993, 15, 1-11. [CrossRef] 
38. Crawford, D.W.; Godbey, G. Reconceptualizing barriers to family leisure. Leis. Sci. 1987, 9, 119-127. [CrossRef]

39. Crawford, J.L.; Stodolska, M. Constraints Experienced by Elite Athletes with Disabilities in Kenya, with Implications for the Development of a New Hierarchical Model of Constraints at the Societal Level. J. Leis. Res. 2008, 40, 128-155. [CrossRef]

40. Darcy, S.; Ollerton, J.; Grabowski, S. "Why Can't I Play?": Transdisciplinary Learnings for Children with Disability's Sport Participation. Soc. Incl. 2020, 8, 209-223. [CrossRef]

41. Darcy, S.; Lock, D.; Taylor, T. Enabling inclusive sport participation: Effects of disability and support needs on constraints to sport participation. Leis. Sci. 2017, 39, 20-41. [CrossRef]

42. McKercher, B.; Darcy, S. Re-conceptualizing barriers to travel by people with disabilities. Tour. Manag. Perspect. 2018, 26, 59-66. [CrossRef]

43. Sotiriadou, K.; Wicker, P. Examining the participation patterns of an ageing population with disabilities in Australia. Sport Manag. Rev. 2014, 17, 35-48. [CrossRef]

44. Dickson, T.J.; Darcy, S.; Johns, R.; Pentifallo, C. Inclusive by design: Transformative services and sport-event accessibility. Serv. Ind. J. 2016, 36, 532-555. [CrossRef]

45. RMOW. Whistler's Journey towards Accessibility; Resort Municipality of Whistler (RMOW): Whistler, BC, Canada, 2010.

46. RMOW. Development of RMOW Accessibility Policy. In Administrative Report to Council; Resort Municipality of Whistler (RMOW): Whistler, BC, Canada, 2020.

47. Sallis, J.F.; Cervero, R.B.; Ascher, W.; Henderson, K.A.; Kraft, M.K.; Kerr, J. An ecological approach to creating active living communities. Annu. Rev. Public Health 2006, 27, 297-322. [CrossRef]

48. Wicker, P.; Hallmann, K.; Breuer, C. Micro and macro level determinants of sport participation. Sport Bus. Manag. 2012, 2, 51-68. [CrossRef]

49. Hoekman, R.; Breedveld, K.; Kraaykamp, G. Sport participation and the social and physical environment: Explaining differences between urban and rural areas in the Netherlands. Leis. Stud. 2017, 36, 357-370. [CrossRef]

50. Eime, R.M.; Casey, M.M.; Harvey, J.T.; Sawyer, N.A.; Symons, C.M.; Payne, W.R. Socioecological factors potentially associated with participation in physical activity and sport: A longitudinal study of adolescent girls. J. Sci. Med. Sport 2015, 18, 684-690. [CrossRef] [PubMed]

51. Lewin, K. Frontiers in Group Dynamics. Hum. Relat. 1947, 1, 5-41. [CrossRef]

52. Veal, A.J.; Darcy, S. Research Methods for Sport Studies and Sport Management: A Practical Guide, 1st ed.; Routledge: Milton Park, UK, 2014.

53. Yin, R.K. Case Study Research: Design and Methods, 5th ed.; Sage Publishers: Thousand Oaks, CA, USA, 2009.

54. Leonard-Barton, D. A Dual Methodology for Case Studies: Synergistic Use of a Longitudinal Single Site with Replicated Multiple Sites. Organ. Sci. 1990, 1, 248-266. [CrossRef]

55. Walker, C.; Whistler Adaptive Sports, Whistler V8E 0K3, BC, Canada. Interview, 2009.

56. Walker, C.; Whistler Adaptive Sports, Whistler V8E 0K3, BC, Canada. Interview, 2010.

57. Walker, C.; Whistler Adaptive Sports, Whistler V8E 0K3, BC, Canada. Interview, 2012.

58. Walker, C.; Whistler Adaptive Sports, Whistler V8E 0K3, BC, Canada. Interview, 2014.

59. Walker, C.; Whistler Adaptive Sports, Whistler V8E 0K3, BC, Canada. Interview, 2016.

60. Walker, C.; Whistler Adaptive Sports, Whistler V8E 0K3, BC, Canada. Interview, 2019.

61. WASP. Annual General Meeting Information Package; Whistler Adaptive Sports Program Society (WASP): Whistler, BC, Canada, 2010.

62. WASP. Annual General Meeting Information Package; Whistler Adaptive Sports Program Society (WASP): Whistler, BC, Canada, 2011.

63. WASP. Annual General Meeting Information Package; Whistler Adaptive Sports Program Society (WASP): Whistler, BC, Canada, 2012.

64. WASP. Annual General Meeting Information Package; Whistler Adaptive Sports Program Society (WASP): Whistler, BC, Canada, 2013.

65. WASP. Annual General Meeting Information Package; Whistler Adaptive Sports Program Society (WASP): Whistler, BC, Canada, 2016.

66. WASP. Annual General Meeting Information Package; Whistler Adaptive Sports Program Society (WASP): Whistler, BC, Canada, 2019.

67. WASP. Annual General Meeting Information Package; Whistler Adaptive Sports Program Society (WASP): Whistler, BC, Canada, 2014.

68. WASP. Annual General Meeting Information Package; Whistler Adaptive Sports Program Society (WASP): Whistler, BC, Canada, 2015.

69. Blackman, D.A.; Benson, A.M.; Dickson, T.J. Enabling event volunteer legacies: A knowledge management perspective. Event Manag. 2017, 21, 223-250. [CrossRef]

70. Accessibility 2024. Available online: https://www.youtube.com/watch?v=2e6BAFCD3MM (accessed on 25 September 2017).

71. Government of Canada. Consulting with Canadians on Accessibility Legislation. Available online: https://www.canada.ca/en/ employment-social-development/programs/disability/consultations/accessibility-legislation.html (accessed on 20 January 2017).

72. RMOW. 2010 Olympic and Paralympic Winter Games Strategic Framework, Version 1; Resort Municipality of Whistler (RMOW), 2010 Winter Games Office: Whistler, BC, Canada, 2006.

73. Osburn, E. Paralympic legacies are legacies for life: Hosting the Paralympic Games in 2010 made Whistler more accessible for everyone. Pique News Magazine, 6 March 2014.

74. Mitchell, A. New home for Whistler's adaptive ski program opens. Pique News Magazine, 31 December 2020.

75. RMOW. Whistler 2020-Moving toward a Sustainable Future. Available online: http:/ / www.whistlercentre.ca/sumiredesign/ wp-content/uploads/2014/02/Whistler2020-Vision.pdf (accessed on 21 April 2018).

76. Editor. Leisure buddies approved. In The Chief/Squamish Chief; Glacier Media Group: Squamish, BC, Canada, 2017.

77. Burke, D. Whistler Adaptive Sports Program Turns 20. Available online: http://s-cdnsrc.dashdigital.com/whistler/winter_2019 ?article_id=1451339\&pg=1\#pg1 (accessed on 27 August 2020). 
78. Miles, M.B.; Huberman, A.M. The Qualitative Researcher's Companion; SAGE: London, UK, 2002.

79. Strauss, A.; Corbin, J. Basics of Qualitative Research: Procedures and Techniques for Developing Grounded Theory, 2nd ed.; SAGE: Thousand Oaks, CA, USA, 1998.

80. Flyvbjerg, B. Five Misunderstandings About Case-Study Research. Qual. Inq. 2006, 12, 219-245. [CrossRef]

81. Vancouver 2010 Bid Corporation. Vancouver 2010 Bid Book; Vancouver 2010 Bid Corporation: Vancouver, BC, Canada, 2003.

82. RMOW. Whistler Visitation. Available online: https:/ / www.whistler.ca/municipal-gov/community-monitoring/whistler-factsand-figures/whistler-visitation (accessed on 15 April 2020).

83. Pique Newsmagazine Staff. Museum Expanding with Online Exhibit of Olympic Bids. Pique News Magazine, 27 May 2003.

84. Darcy, S. The politics of disability and access: The Sydney 2000 Games experience. Disabil. Soc. 2003, 18, 737-757. [CrossRef]

85. Government of Canada. Policy on Sport for Persons with a Disability. Available online: http://canada.pch.gc.ca/eng/14145136 35858/1414513676681 (accessed on 28 May 2016).

86. Government of Canada. Promoting Rights of Persons with Disabilities. Available online: https://www.international.gc.ca/worldmonde/issues_development-enjeux_developpement/human_rights-droits_homme/rights_disabilities-droits_handicapees. aspx?lang=eng (accessed on 27 August 2020).

87. Province of British Columbia. Accessibility 2024: Making B.C. the Most Progressive Province in Canada for People with Disabilities by 2024; Province of British Columbia: Victoria, BC, Canada, 2014. Available online: http:/ / www2.gov.bc.ca/gov/DownloadAsset? assetId=4E4879D2986E4E8CB3F6F757F59978D5\&filename=accessibility2024_update_web.pdf (accessed on 15 June 2015).

88. Province of British Columbia. Accessibility 2024: Making B.C. the most progressive province in Canada for people with disabilities by 2024. In June 2015 One Year Progress Update; Province of British Columbia: Victoria, BC, Canada, 2015. Available online: http://www2.gov.bc.ca/assets/gov/government/about-the-bc-government/accessible-bc/accessibility-20 24/docs/accessibility2024-1-year-progress.pdf (accessed on 7 July 2015).

89. SSCHR. Level the Playing Field: A Natural Progression from Playground to Podium for Canadians with Disabilities; Standing Senate Committee on Human Rights (SSCHR), Ed.; Government of Canada: Ottawa, ON, Canada, 2012.

90. Accessible Canada Act S.C. 2019, c. 10. 2019. Available online: https://laws-lois.justice.gc.ca/eng/acts/A-0.6/page-1.html\#h-11 53392 (accessed on 27 August 2020).

91. UN. Transforming our world: The 2030 agenda for sustainable development. In New York: United Nations, Department of Economic and Social Affairs; United Nations (UN): Geneva, Switzerland, 2015.

92. VANOC. Business Plan. and Games Budget; Vancouver Organizing Committee for the 2010 Olympic and Paralympic Winter Games (VANOC): Vancouver, BC, Canada, 2007.

93. VANOC. Vancouver 2010 Bid Report; The Vancouver Organizing Committee for the 2010 Olympic and Paralympic Winter Games: Vancouver, BC, Canada, 2009.

94. National Research Council of Canada. Building Standards for the Handicapped, 1965. Supplement no. 7 to the National Building Code of Canada; National Research Council Canada, Associate Committee on the National Building Code: Ottawa, ON, Canada, 1965.

95. National Research Council of Canada. Building Standards for the Handicapped, 1980; NRCC No. 17669; Associate Committee on the National Building Code, National Research Council of Canada: Ottawa, ON, Canada, 1980.

96. Perks, T. Exploring an Olympic "legacy": Sport participation in Canada before and after the 2010 Vancouver Winter Olympics. Can. Rev. Sociol. 2015, 52, 462-474. [CrossRef]

97. RMOW. Delivering the Dream: Whistler-Host Mountain Resort, 2010 Olympic and Paralympic Winter Games; Resort Municipality of Whistler (RMOW): Whistler, BC, Canada, 2008.

98. Riediger, M.; Dickson, T.J.; Walker, C. The Ups and Downs of Adaptive MTB. In Proceedings of the Mountain Bike Tourism Symposium, Whistler, BC, Canada, 2-4 October 2019.

99. Hudson, S.; Hinch, T.; Walker, G.; Simpson, B. Constraints to Sport Tourism: A Cross-Cultural Analysis. J. Sport Tour. 2010, 15, 71-88. [CrossRef]

100. O'Brien, D.; Chalip, L. Executive training exercise in sport event leverage. Int. J. Cult. Tour. Hosp. Res. 2007, 1, 296-304. [CrossRef]

101. Schulenkorf, N. Managing sport-for-development: Reflections and outlook. Sport Manag. Rev. 2017, 20, 243-251. [CrossRef]

102. Destination British Columbia. Sport Tourism: The Essential Guide to Understanding and Developing Sport Tourism in BC; Destination British Columbia Corp: Vancouver, BC, Canada, 2013.

103. IOC. Promoting Tourism; International Olympic Committee (IOC): Lausanne, Switzerland, 2020. 